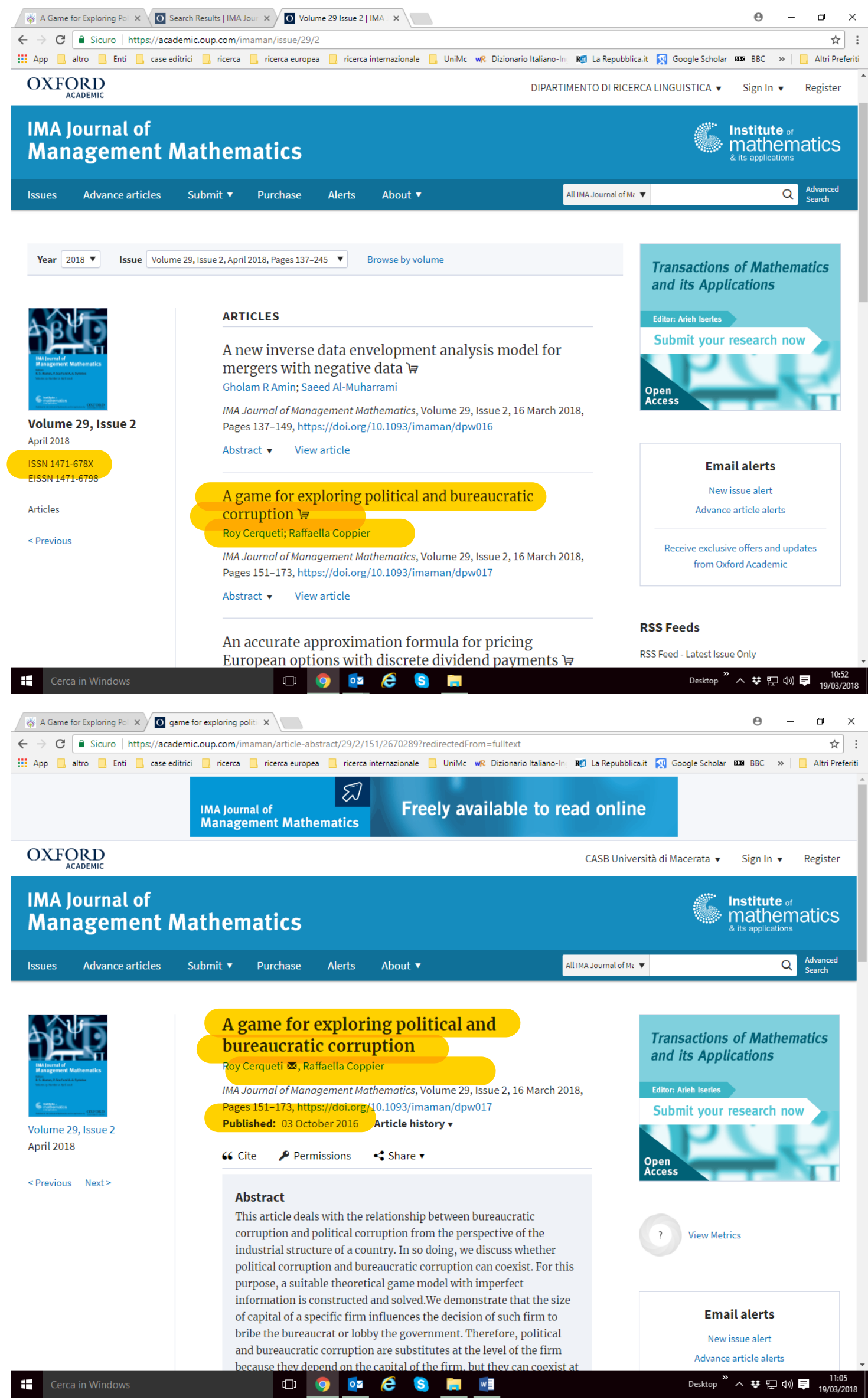


IMA Journal of Management Mathematics (2016) 00, 1-23

doi: 10.1093/imaman/dpw017

\title{
A game for exploring political and bureaucratic corruption
}

\author{
Roy CERqueti* AND RAFFAella CoPpIER \\ Department of Economics and Law, University of Macerata, via Crescimbeni 20, 62100 Macerata, Italy \\ *Corresponding author: Email: roy.cerqueti@unimc.it
}

[Received on 9 December 2015; accepted on 5 September 2016]

\begin{abstract}
This article deals with the relationship between bureaucratic corruption and political corruption from the perspective of the industrial structure of a country. In so doing, we discuss whether political corruption and bureaucratic corruption can coexist. For this purpose, a suitable theoretical game model with imperfect information is constructed and solved. We demonstrate that the size of capital of a specific firm influences the decision of such firm to bribe the bureaucrat or lobby the government. Therefore, political and bureaucratic corruption are substitutes at the level of the firm because they depend on the capital of the firm, but they can coexist at a macro level. Some numerical experiments validate the theoretical model.
\end{abstract}

Keywords: Game with imperfect information; bureaucratic corruption; political corruption; industrial organization.

\section{Introduction}

Corruption is not a straightforward, and must be interpreted in context. In particular, political corruption is fundamentally different from bureaucratic corruption. The latter refers to the payment of bribes for services in regards to the implementation of regulations, while political corruption refers to influencing the formulation of laws and other public policies through illicit or non-transparent means to achieve an economic advantage (see e.g.: Hellman \& Kaufmann, 2001).

Some authors (see e.g. Damania et al., 2004; Harstad \& Svensson, 2011; Campos \& Giovannoni, 2007) call 'lobbying' all actions aimed ar influencing policy-makers, and use 'corruption' for bureaucratic corruption only. Strictly speaking, this definition is not completely satisfactory since it fails to distinguish between legal and illegal means of influencing the formulation of public policies, regulations and rules. In fact, considering only lobbying and bureaucratic corruption would be correct in some political systems, notably the USA, where the provision of monetary payments to policy-makers is perfectly legal (lobbying) but it is not correct for other political systems where the same exact payments are illegal and considered as a form of corruption (political corruption). From this point of view, a broader definition of corruption encompassing all illegal procedures seems more useful. Indeed, according to Kaufmann (2009), corruption should include all actions leading to a bending of the rules, even when strictly speaking they are legal. More specifically, political corruption can be distinguished from other forms of political influence, like lobbying, based on the procedures through which private interests interact with the political sphere. Political corruption takes place ensuring private gains to politicians through informal, non-transparent and obviously preferential channels of access.

In our article, we analyse the relationship between political corruption and bureaucratic corruption in order to understand whether they can coexist at an aggregated level.

For this purpose, we construct and develop a theoretical game with imperfect information. This approach is based on two scientific premises: first, corruption can be found only in the case of interacting

(C) The authors 2016. Published by Oxford University Press on behalf of the Institute of Mathematics and its Applications. All rights reserved. 
economic agents; second, since illegal activities may be detected by controllers, corruption is a risky activity. We refer readers to Moulin (1986); Gibbons (1992) and Mesterton-Gibbons (2000) for a survey of game theory with applications in the economic and social sciences.

The game is played by three classes of agents: politicians, bureaucrats and firms. Firms have the possibility to comply with regulations or not. As in other studies, we assume that politicians and bureaucrats are open to bribery (see e.g. Chander \& Wilde, 1992; Hindriks et al., 1999; Sanyal et al., 2000). Moreover, the game is played in a stepwise form till a given time threshold. We address the reader to Section 2 for a detailed description of the game, and here we limit ourselves to pointing out that randomness is identified by the presence of a positive probability to be detected in a corrupt transaction by the authorities. Political corruption may appear only at the beginning of the game-i.e.: time $t=0$-when firms have the opportunity to bribe the politicians to obtain changes in a rule that remains in force for the entire period. Moreover, a term capturing the effectiveness of political corruption is suitably introduced. In so doing, we include in the theoretical model the evidence that modifying norms and laws is a reversible activity, the reversibility being linked to the political and social situation and to the life cycle of the administration in charge. Hence, political corruption may have a weak effect.

The theoretical results obtained by solving the game are validated through extensive simulations. For this purpose, we assume that a Gamma distribution describes the population of firms by capital level. As a consequence, it is possible to build several scenarios-by appropriately selecting the Gamma parameters - and comparing them.

Our article is not the first that deals with corruption from a game theory perspective, and some contributions are particularly worth to mentioning. Macrae (1982) develops a theoretical game model for corruption in underdeveloped countries. Pasetta (1999) views bribes as externalities in a dividemoney game. Celentani \& Ganuza (2002) introduce a game model to examine how the inner structure of corruption - conceived as of corrupt individuals and groups-affects corruption control. Cerqueti \& Coppier $(2009,2011)$ discuss the role of corruption in economic growth by considering games in static and dynamic frameworks. Ethnic fractionalization and its relationship with corruption are the main themes of Cerqueti et al. (2012) and Cerqueti \& Coppier (2014). The first article by Cerqueti differs from the second and from the present one, being based on a game with complete information. Cerqueti \& Coppier (2013) discuss the role of incentives for tax evasion controllers open to bribery, and study the problem through a Bayesian game. Majumdar \& Yoo (2012) explore the phenomenon of influence peddling by developing first a one-stage game, and then a repeated one. Cerqueti \& Coppier (2016) presents a game where environmental protection represents a tool for morally persuading firms to be compliant with the regulation.

None of the articles cited above examines the relationship between bureaucratic corruption and political corruption. In this respect, we are particularly close to Harstad \& Svensson (2011), who face the problem of selection between lobbying and bureaucratic corruption through a game theoretical model. However, the present article is radically different from Harstad \& Svensson (2011) for some relevant reasons: first - as already stated above-we refer to a broad concept of political corruption, which is an illegal activity. Differently, the quoted article considers lobbying as a legal procedure to influence the regulation; second, we include explicitly the industrial structure of the country among the ingredients of the model. In this respect, firm size proxies the country's industrial structure rather than the level of development of the country itself. In so doing, the role of the capital distribution of the firms in driving towards political or bureaucratic corruption is explored; third, we introduce a term-denoted as $\alpha$, see below-which measures the persistency of the effects of the lobbying activity. In particular, we model the evidence that political corruption might be more or less effective on the basis of how and if politicians intend to implement the promised policies. 
To the best of our knowledge, this is the first game model dealing with the problem of the coexistence of these two types of corruptions and including also the industrial structure of the considered country. However, we are in the mainstream when dealing with agents who are profit maximizers and whose relative bargaining powers are fully considered (see e.g. Anthropelos et al., 2014).

The above-described generalization of the Harstad \& Svensson (2011)'s framework leads to a rather complicated setting. However, such complexity is rewarded by interesting outcomes. We here demonstrate that the relationship between political and bureaucratic corruption is linked with the specific industrial structure of a country. Moreover, we also find that a sufficiently high capital level of the firm is a necessary condition for engaging in political corruption. But we also find that such a condition is not sufficient for making it economically profitable. This outcome is due to the realistic assumption that the politicians cannot grant the permanent and effective changing of the rule (see the above mentioned parameter $\alpha$ in the model).

The article is organized as follows. In Section 2, we present the model. In Section 3, we describe the timing of the game and provide the main results. Section 4 contains some numerical experiments validating the theoretical results. Section 5 is devoted to the economic interpretation of the outcomes of the article. The last section offers some conclusive remarks.

\section{Theoretical model}

Consider an economy composed of three players: high level public official (politician), low level public official (bureaucrat) and the firm. The game is played for the first time at date $t=0$, and then repeated each time until a final date $T>0$.

The payoff vectors will be indicated with a triple

$$
\underline{\pi}=\left(\pi^{(F)}, \pi^{(B)}, \pi^{(P)}\right), \quad \forall t=0,1, \ldots, T,
$$

where $\pi^{(F)}, \pi^{(B)}$ and $\pi^{(P)}$ represent the payoffs of the firm, the bureaucrat and the politician, respectively.

We assume that, even if the firm is required to comply with the laws and regulations, it may decide not to do it. In the non-compliant case, it may seek to avoid the application of the law time-by-time by bribing a bureaucrat (bureaucratic corruption) or it can seek to change the existing legislation at time $t=0$ in its favour by bribing a politician (political corruption) ${ }^{1}$. In practice, politicians are assumed to emanate laws only at time $t=0$, and such laws stand in force for the whole period $[0, T]$. The terminal time $T>0$ may be viewed as the lifetime-in electoral terms - of the politician. After $T$, elections take place, and the changing of the government leads to a new framework for writing rules and laws.

One can think for example, to the case of polluting firms whose emissions are regulated through environmental laws which fix a pollution tax. For the sake of simplicity, we will refer hereafter to this paradigmatic case.

In order to regulate pollution emissions, two levels of public official are necessary: high-level public officials, i.e. politicians, who formulate environmental policies, and low-level public officials, i.e. bureaucrats, who are responsible for implementing at each time these environmental policies (e.g. through inspections). Notice that bureaucratic and political corruption are mutually exclusive. This means that a given firm cannot decide to implement political corruption at time $t=0$ and also bureaucratic corruption

\footnotetext{
${ }^{1}$ In our model we consider only monetary bribes both for politicians and bureaucrats. For a detailed analysis of different types of bribes (monetary and non-monetary) and their relative bargaining strength see, for example, Rodrigues-Neto (2014).
} 
in the period $[0, T]$. In fact, the targets of the two types of corruptions are identical, i.e. to remove the pollution tax.

We assume that the government cannot directly observe the level of pollution emitted by the firm and therefore, employs environmental inspectors (bureaucrats) to check pollution level in order to counter environmental evasion or prevent pollution. We consider the relationship between political corruption, bureaucratic corruption and industrial organization. There is an important difference between the two forms of non-compliant behaviour by the firm: bureaucratic corruption bends the rules only temporary (for one period in our model) because firms deal with different bureaucrats over time (in each period), while political corruption implies a legislative change and, therefore, alters the status quo for a longer period.

In fact, even if political corruption may take place only at time $t=0$, in our model we consider that the effects of the political corruption, i.e. the change of the rule, refer to a period which goes from $t=0$ to $t=T$. Moreover, if the firm engages in political corruption, then the firm exits the game and cannot implement bureaucratic corruption or compliance in subsequent years. Conversely, if political corruption is not selected at $t=0$, then at any time $t=1, \ldots, T$ the firm can choose bureaucratic corruption or compliance. As we shall see in the model formalization (see next Section), there is no capital accumulation and payoffs do not change over time for bureaucratic corruption and for compliance. Therefore, the decision of implementing bureaucratic corruption or compliance at time $t=0$ will be repeated identically at any time $t=1, \ldots, T$. Furthermore, the comparison between the payoffs in the three cases - which leads to the decision of the firms-requires an identical time horizon. Hence, the payoffs in all the cases should be compared at time $T$, given that the effects of political corruption are long-term. To sum up: decisions are driven by what is expected at the terminal time $T$ of the game.

In both cases, the effects of non-compliant behaviours apply only to non-compliant firms. More precisely, changing the rules helps only the firms bribing the politicians, and free-riding is not allowed.

It should be noted that the effects of political corruption are strongly linked to several politicallybased factors, such as the stability of the administration or the outcomes of 'midterm' elections. In this respect, following Fredriksson \& Wollscheid (2008), we assume that the politicians remain in office and are able to implement the promised policy till time $t=T$. However, a change in the political situation may cause a weakening of the legislative interventions produced by lobbying activity. To capture this aspect, we introduce a parameter $\alpha \in[0,1]$, which may be viewed as a proxy of lobbying effectiveness. More specifically, as the value of $\alpha$ increases, the alteration of the status quo in time and size is more evident. The corner cases are $\alpha=0$-which means 'no effects caused by political corruption'—and $\alpha==1$-which describes a permanent effect.

Each firm has to deal with some regulations that hamper its activity (e.g. environmental regulation). Unlike Harstad \& Svensson (2011), we consider firms heterogeneous with respect to capital level ${ }^{2}$. This allows us to carry out an analysis of the industrial structure of the country. Thus, the production of the $j$-th firm is:

$$
y_{j}=g\left(k_{j}\right)=r k_{j}
$$

where $r$ is a productivity parameter and $k_{j}$ is the specific capital level of the $j$-th firm.

\footnotetext{
${ }^{2}$ In our model we assume heterogeneity for firms and homogeneity for public officials. Specifically, firms can be differentiated in terms of their capital, while politicians/bureaucrats are not differentiated. For an analysis of public officials who differ in wealth see e.g. Fabrizi \& Lippert (2012).
} 
If the firm complies with regulation, it has to pay a proportional cost $c$ on capital level $k_{j}$.

The $j$-th firm might have an economic incentive to corrupt the politicians in order to change the regulation. For simplicity, we assume that in this case-i.e. $\alpha=1$ - the new law provides no emission cost for the firm. Thus, the firm must, on the basis of its expected costs of compliance with the rules $c k_{j}$, evaluate its economic incentive with respect to political corruption.

We assume that the politician wants a bribe $P$ at time $t=0$ for changing the current regulation. Changing the rules benefits all firms which, in equilibrium, find it worthwhile to corrupt the politician. Hence, they may share the cost of political corruption. But, as we said, the firms are heterogeneous with respect to their capital level $k_{j}$. Therefore, the politician asks for a bribe $p_{j}$ which is the Nash solution of a bargaining game between the $j$-th firm and the politician (see Nash, 1950). As we will see, we assume, without loss of generality, that the bargaining strength of the firm is equal to $\beta$ and it is the same versus both politicians and bureaucrats.

In order to describe the heterogeneity of the capital, we consider the cumulative probability function which defines the distribution of individual capital level $F\left(k_{j}\right)$, where $j$ is the specific firm. The density function of $F$ is denoted as $f$. The shape of the function $f$ provides good information on the general level of firm capital, used as a proxy for industrial structure. In particular, the symmetry properties of the function $f$ provide information on the distribution of the firms in terms of high or low capital level ${ }^{3}$.

Given the heterogeneity of firms, their behaviour vary with their capital level $k_{j}$. We assume that the political and bureaucratic corruption can be discovered with an exogenous probability $q$. If the political corruption is not discovered, the benefit gained by the $j$-th firm is represented by the lower emission cost for the firm $(1-\alpha) c k_{j}$ for $T+1$ times. If political or bureaucratic corruption is discovered, then the firm is fined for an amount $m^{4}$, while politicians and bureaucrats must pay a constant fine $\lambda^{P}$ and $\lambda^{B}$, respectively.

Thus, the necessary condition for the $j$-th firm for participate to political corruption is that the current (at time $t=0$ ) payoff of engaging in political corruption is greater than the expected cost of political corruption. Since political corruption may appear only at the beginning of the period, as already preannounced above, then the payoff of the political corruption is considered at time $t=0$.

The payoff at time $t=0$ of the case of political corruption is given by:

$$
\underline{\pi}_{P}= \begin{cases}\left(r k_{j}-(1-\alpha) c k_{j}-p_{j} ; w^{B} ; w^{P}+P\right), & \text { with probability } 1-q ; \\ \left(r k_{j}-c k_{j}-m ; w^{B} ; w^{P}-\lambda^{P}\right), & \text { with probability } q,\end{cases}
$$

where $w^{B}$ and $w^{P}$ are the salaries earned by the bureaucrat and the politician, respectively.

Therefore, the necessary condition for the firm to engage in political corruption is:

$$
q\left(r k_{j}-c k_{j}-m\right)+(1-q)\left(r k_{j}-p_{j}-(1-\alpha) c k_{j}\right) \geq 0,
$$

\footnotetext{
${ }^{3}$ Since $f$ is a centered symmetric function, then the Country has an average level of capital, and the number of large firms balances the number of little firms. The case of $f$ asymmetric to the left can be associated to a Country where most firms are little, while $f$ is asymmetric to the right in Countries where most firms are large. Therefore, for our analysis to be complete, we need to provide a random law for the capital level which may describe the generality of the cases, depending on the value of some parameters. This goal can be achieved by adopting a probability law commonly used in a rather mathematical context, namely: the Gamma distribution. In fact, of all the distribution functions of random variables with support in $[0, \infty]$, the Gamma law seems to be the more appropriate choice for $F$, since it has features that make it suitable for modeling the different capital level of the firms, belonging to a given Country, i.e. the industrial structure.

${ }^{4}$ The amount of the fine $m$ is assumed to be sufficiently large to include the bribe paid by the firm, which therefore does not appear explicitly in the payoffs.
} 
Inequality (4) is equivalent to

$$
k_{j} \geq \frac{q m+p_{j}(1-q)}{r-c[q+(1-\alpha)(1-q)]} .
$$

We take condition (5) as the requirement to be satisfied by the capital of the $j$-th firm to let the implementation of political corruption be possible.

Politicians might decide not to change the rule. In this case, the firm must decide whether to comply or to bribe the bureaucrat.

Analogously, in the case in which the $j$-th firm does not find it worthwhile to engage in political corruption, the firm must decide every year whether to comply with environmental regulations or not. In the latter case, the non-compliant $j$-th firm is checked and it can corrupt the bureaucrat through a bribe $b_{j}$, for each $t$, in order for the non-compliance not to be reported. The value of the bribe is the result of a bargaining process between firm and bureaucrat that takes place in each period.

\section{The game: description and solution}

Given the framework described above, we can formalize the economic problem into a four-period game with complete and imperfect information.

For a clear exposition, we present the game is a stepwise form. Note that the proposed timing of the game-which is the most realistic one-has not effect on the identification of the equilibria of the game. The reason is that optimal bribe levels and equilibria depend on the payoffs of firm/bureaucrats/politicians, which are independent of the timing of the game.

The stepwise scheme of the game is the following:

\subsection{Time $t=0$}

\section{First stage}

The $j$-th firm must decide if comply with regulation or not. If the $j$-th firm will find it worthwhile to comply, the payoff vector is:

$$
\underline{\pi}_{1}=\left(r k_{j}-c k_{j} ; w^{B} ; w^{P}\right) .
$$

If the $j$-th firm decides to not comply, the game continue at Second stage.

\section{Second stage}

Two cases must be distinguished: if condition (5) is not true, then the firm may implement only bureaucratic corruption; otherwise, the firm may consider also political corruption.

Case I: condition (5) holds The tree of the game can be found in Fig. 1.

The $j$-th firm must decide whether corrupt a politician in order to change the regulation or to bend the rule.

If the firm bends the rule, the game continues to the Third stage - II (see below, Case II).

If the firm decides to corrupt the politician, the game continues to the Third stage - I. 


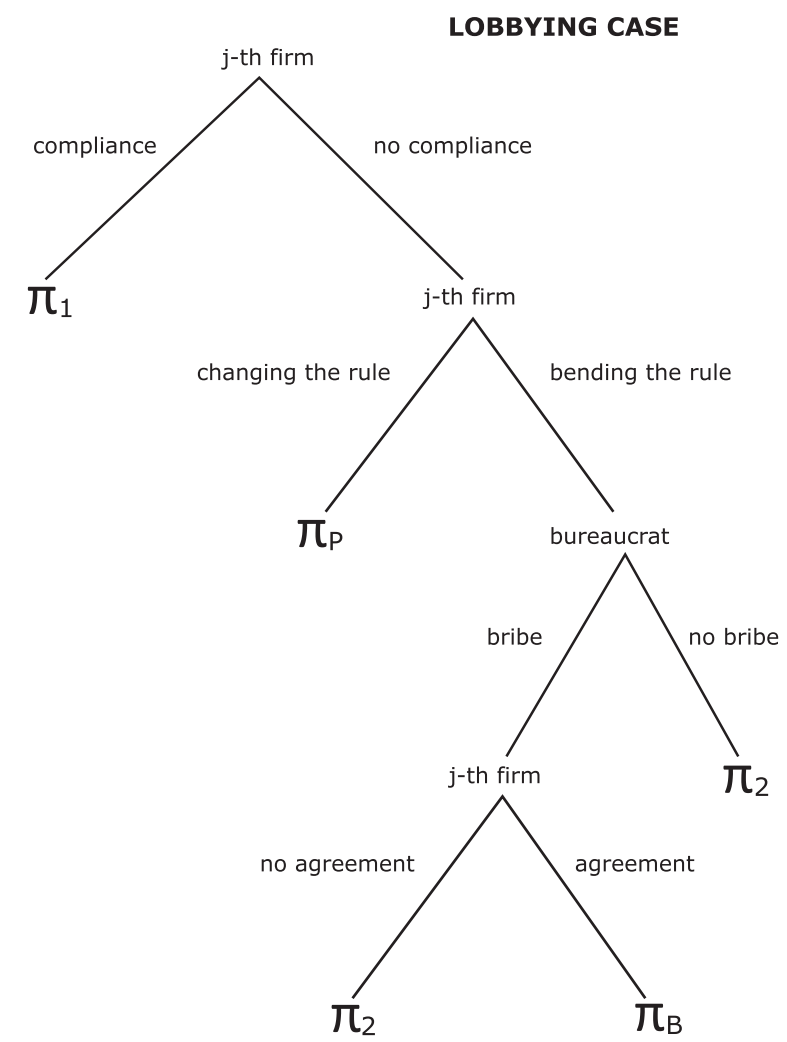

FIG. 1. Tree of the game in the lobbying case.

\section{Third stage - I}

In this stage the politician must decide whether to change the rule or not.

If the rule is not changed, then the firm must decide whether to comply or to bend the rule. In the latter case, the game continues to the Third stage - II (see below, Case II). If the firm complies, then the game ends with the following payoff vector:

$$
\underline{\pi}_{1}=\left(r k_{j}-c k_{j} ; w^{B} ; w^{P}\right)
$$

If the politician changes the rule, then the corrupt transaction can be inspected with a probability $q$. If corruption is detected, the firm suffers of a punishment $m$ while the politician pays an economic fine $\lambda^{P}$. Otherwise, we have undiscovered corruption: the firm pays the cost of political corruption $p_{j}^{N B}$ — which is the Nash solution of a bargaining game-but obtains the benefit due to this illegal activity.

The game ends with random payoff vector given by:

$$
\underline{\pi}_{P}= \begin{cases}\left(r k_{j}-(1-\alpha) c k_{j}-p_{j}^{N B} ; w^{B} ; w^{P}+P\right), & \text { with probability } 1-q ; \\ \left(r k_{j}-c k_{j}-m ; w^{B} ; w^{P}-\lambda^{P}\right), & \text { with probability } q .\end{cases}
$$




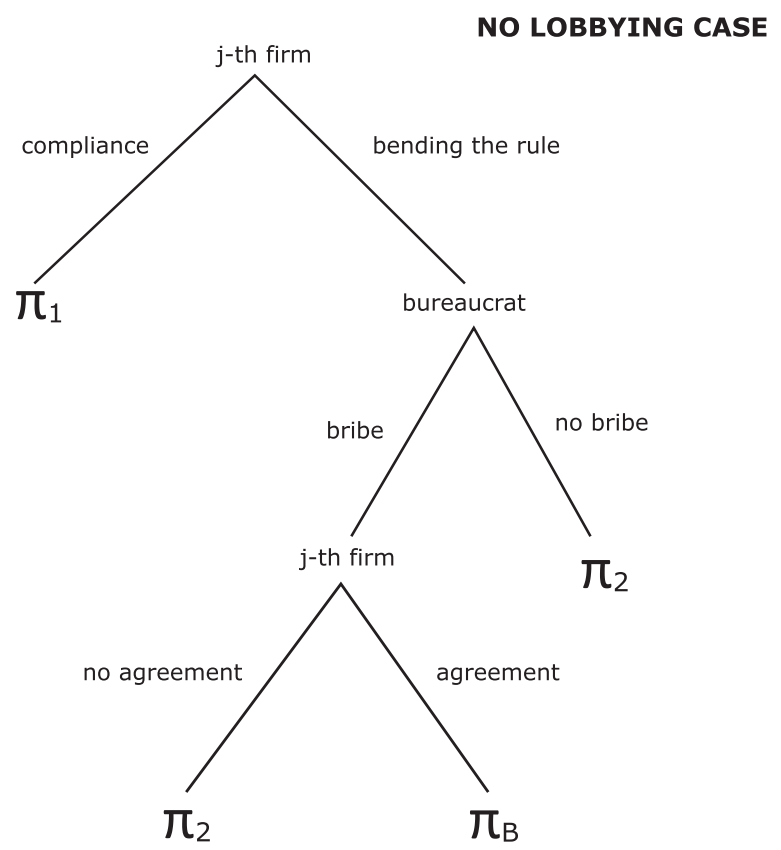

FIG. 2. Tree of the game in the case of no lobbying.

The decision node of the politician leads to a condition to be satisfied by the quantity $P$ in order to have the change of the rule. Such a condition states a relationship between some parameters of the model. We will formalize the assumption on $P$ leading to the changing of the rule by the politician in a devoted Proposition (see Proposition 3.1), and then consider separately the two cases coming out from such a condition. In so doing — as we will see- the Third stage-I leads to the splitting of the game in two different parts.

Case II: condition (5) does not hold We present the tree of the game in Fig. 2.

The $j$-th firm must decide whether bend the rule or comply. If the $j$-th firm decides to bend the rule, the game continues at stage three.

\section{Third stage - II}

The bureaucrat, who checks the $j$-th firm, must decide whether to report the environmental evasion or to ask for a bribe $b>0$.

In the case in which the bureaucrat decides to not ask for a bribe, i.e. to report the bending of rule, the $j$-th firm must pay a fine $m$. Then, the game ends with the following payoff vector:

$$
\underline{\pi}_{2}=\left(r k_{j}-c k_{j}-m ; w^{B} ; w^{P}\right) .
$$

Otherwise, the game continues to stage four. 


\section{Fourth stage - II}

If the bureaucrat asks the $j$-th firm for a bribe $b_{j}>0$, then the firm must decide whether to negotiate such a bribe or refuse the negotiation. When the bribe is refused by the $j$-th firm, then the game ends with the following payoff vector:

$$
\underline{\pi}_{2}=\left(r k_{j}-c k_{j}-m ; w^{B} ; w^{P}\right) .
$$

If the polluting firm accepts to negotiate the bribe, then the negotiation starts and the two parties will find an agreement on the the bribe $b_{j}^{N B}$, which corresponds to the Nash solution to a bargaining game. The corrupt transaction may be inspected with probability $q$. If corruption is discovered, then the firm pays a fine $m$ and the bureaucrat a fine $\lambda^{B}$. Otherwise, we have undetected corruption.

The game ends with random payoff vector given by:

$$
\underline{\pi}_{B}= \begin{cases}\left(r k_{j}-b_{j}^{N B} ; w^{B}+b_{j}^{N B} ; w^{P}\right), & \text { with probability } 1-q ; \\ \left(r k_{j}-c k_{j}-m ; w^{B}-\lambda^{B} ; w^{P}\right), & \text { with probability } q .\end{cases}
$$

\subsection{Time $t=1, \ldots T$}

The game is repeated as in Subsection 3.1. The only remarkable difference is that political corruption does not appear as a decision node of the game. Indeed, as already stated in the setting of the model, political corruption is a permanent corruption, which affects the entire set of the future realizations of the payoffs. However, the effects of political corruption propagates at time $t>0$, as the terms $\alpha$ 's clearly affirm.

For the convenience of the reader, we write the game in this case.

\section{First stage}

The firm decides whether comply or not. In the former case, the payoff vector is:

$$
\underline{\pi}_{1}=\left(r k_{j}-c k_{j} ; w^{B} ; w^{P}\right)
$$

In the latter case, the firm bends the rule and the game continues to Second stage .

\section{Second stage}

The bureaucrat must decide whether to report the environmental evasion or to ask for a bribe $b>0$. In the no-bribe case, the $j$-th firm pays a fine $m$, and the game ends with the following payoff vector:

$$
\underline{\pi}_{2}=\left(r k_{j}-c k_{j}-m ; w^{B} ; w^{P}\right) .
$$

Otherwise, the game continues to stage four. 


\section{Third stage}

If the bureaucrat asks the $j$-th firm for a bribe $b>0$, then the firm decides to accept or refuse it. In the latter case, the game ends with the following payoff vector:

$$
\underline{\pi}_{2}=\left(r k_{j}-c k_{j}-m ; w^{B} ; w^{P}\right) .
$$

Conversely, in the former case, then the negotiation leads to the bribe $b_{j}^{N B}$, which corresponds to the Nash solution to a bargaining game. Also in this case, $q$ represents the probability of inspection of the corrupt transaction. The fine in case of corruption detection is $m$ for the firm and $\lambda^{B}$ for the bureaucrat. Otherwise, we have undetected corruption.

The game ends with random payoff vector given by:

$$
\underline{\pi}_{B}= \begin{cases}\left(r k_{j}-b^{N B} ; w^{B}+b_{j}^{N B} ; w^{P}\right), & \text { with probability } 1-q ; \\ \left(r k_{j}-c k_{j}-m ; w^{B}-\lambda^{B} ; w^{P}\right), & \text { with probability } q .\end{cases}
$$

\subsection{Solution of the game}

The first result states the condition to be satisfied in order to have the changing of the rule by the politician. This is an anticipation of the extended solution of the game through backward induction (see Propositions 3.4 and 3.5), and it is reported here for the sake of simplicity.

PROPOSITION 3.1 Assume that condition (5) holds. The regulation is changed by the politician if and only if

$$
P>\frac{q \lambda^{P}}{1-q}
$$

Proof. The politician changes the regulation if and only if

$$
\mathbf{E}\left[\pi_{P}^{(P)}\right]-\pi_{1}^{(P)}>0
$$

where $\mathbf{E}$ indicates the expected value operator. By (7) and (8) we have that condition (17) is equivalent to (16).

In order to proceed to the solution of the game, we now provide an explicit expression of the bribe $b_{j}^{N B}$ for the bureaucrat and the bribe $p_{j}^{N B}$ for the politician.

Proposition 3.2 For each $t=0,1, \ldots, T$ and firm $j$, there is a unique bribe $b^{N B}$, as the Nash solution to the bargaining game, given by:

$$
b_{j}^{N B}=(1-\beta)\left(c k_{j}+m\right)+\frac{\beta q \lambda^{B}}{1-q} .
$$

where $\beta$ and $1-\beta$ are the parameters in $[0,1]$ that can be interpreted as measures of bargaining strength, of the firm and the bureaucrat, respectively. 
Proof. Let us fix $t=0,1, \ldots, T$ and let $\underline{\phi}_{\Delta}(t)=\left(\phi_{\Delta}^{(F)}(t), \phi_{\Delta}^{(B)}(t)\right)$ be the vector of the differences in the expected payoffs between the case of agreement and disagreement regarding the bribe between the $j$-th firm and the bureaucrat, i.e.

$$
\left\{\begin{array}{l}
\phi_{\Delta}^{(F)}(t)=\mathbf{E}\left[\pi_{B}^{(F)}(t)\right]-\pi_{2}^{(F)}(t) \\
\phi_{\Delta}^{(B)}=\mathbf{E}\left[\pi_{B}^{(B)}(t)\right]-\pi_{2}^{(B)}(t)
\end{array}\right.
$$

By following the generalized Nash bargaining theory, the bribe of agreement comes out from:

$$
\max _{b_{j} \in(0,+\infty)}\left\{\phi_{\Delta}^{(F)}(t)\right\}^{\beta} \cdot\left\{\phi_{\Delta}^{(B)}(t)\right\}^{1-\beta}
$$

i.e.:

$$
\max _{b_{j} \in(0,+\infty)}\left[(1-q)\left(b_{j}+c k_{j}+m\right)\right]^{\beta} \cdot\left[-q \lambda^{B}+(1-q) b_{j}\right]^{(1-\beta)} .
$$

The objective function in (24) is a reversed U-shaped function in $b_{j}$. Therefore, the first order condition leads to the bribe of agreement:

$$
b_{j}^{N B}=(1-\beta)\left(c k_{j}+m\right)+\frac{\beta q \lambda^{B}}{1-q},
$$

which is the unique bureaucratic equilibrium bribe in the last sub-game.

Since the interesting part of the game is that related to the behaviour of the firm, we here consider only the payoffs of the firms. The aggregate expected profits $\Pi$ at time $T$ of the $j$-th firm vary, depending on the case, as follows:

$$
\underline{\Pi}=\left\{\begin{array}{l}
\Pi_{i}=\sum_{t=0}^{T}\left(r k_{j}-c k_{j}\right), \\
\Pi_{i i}=\sum_{t=0}^{T}\left[q\left(r k_{j}-c k_{j}-m\right)+(1-q)\left(r k_{j}-b_{j}^{N B}\right)\right], \\
\Pi_{i i i}=\sum_{t=0}^{T}\left(r k_{j}-c k_{j}-m\right), \\
\Pi_{i v}=\sum_{t=0}^{T}\left[q\left(r k_{j}-c k_{j}-m\right)+(1-q)\left(r k_{j}-(1-\alpha) c k_{j}\right]-(1-q) p_{j}^{N B},\right.
\end{array}\right.
$$

where the subscripts point intuitively to the related case in the list presented at the end of Section 2.

As we saw, the politician ask for a bribe $p_{j}$ which is a Nash solution of a bargaining game between the firm and the politician.

Proposition 3.3 For each $t=0,1, \ldots, T$, there is a unique bribe $p_{j}^{N B}$, as the Nash solution to the bargaining game, given by:

$$
p_{j}^{N B}=(T+1)\left[(1-\beta) \alpha c k_{j}-\frac{(1-\beta) m q}{(1-q)}+\frac{\beta q \lambda^{P}}{(1-q)}\right] .
$$


where $\beta$ and $1-\beta$ are the parameters in $[0,1]$ that can be interpreted as measures of bargaining strength of the firm and the politician, respectively.

Proof. Let us fix $t=0,1, \ldots, T$ and let $\underline{\phi}_{\Delta}(t)=\left(\phi_{\Delta}^{(F)}(t), \phi_{\Delta}^{(P)}(t)\right)$ be the vector of the differences in the expected payoffs between the case of agreement and disagreement regarding the bribe between the $j$-th firm and the politician, i.e.

$$
\left\{\begin{array}{l}
\phi_{\Delta}^{(F)}(t)=\mathbf{E}\left[\pi_{i v}^{(F)}\right]-\pi_{i}^{(F)} \\
\phi_{\Delta}^{(P)}=\mathbf{E}\left[\pi_{i v}^{(P)}\right]-\pi_{i}^{(P)}
\end{array}\right.
$$

By following the generalized Nash bargaining theory, the bribe of agreement comes out from:

$$
\max _{p_{j} \in(0,+\infty)}\left\{\phi_{\Delta}^{(F)}(t)\right\}^{\beta} \cdot\left\{\phi_{\Delta}^{(P)}(t)\right\}^{1-\beta},
$$

i.e.:

$$
\left.\max _{p_{j} \in(0,+\infty)}\left[(1-q)(T+1) \alpha c k_{j}-(T+1) m q-(1-q) p_{j}\right)\right]^{\beta} \cdot\left[-q \lambda^{P}(T+1)+(1-q) p_{j}\right]^{(1-\beta)} .
$$

The objective function in (24) is a reversed U-shaped function in $p_{j}$. Therefore, the first order condition leads to the bribe of agreement:

$$
p_{j}^{N B}=(T+1)\left[(1-\beta) \alpha c k_{j}-\frac{(1-\beta) m q}{(1-q)}+\frac{\beta q \lambda^{P}}{(1-q)}\right] .
$$

which is the unique equilibrium political bribe in the last sub-game.

By (22), we can rewrite condition (5) for having political corruption as

$$
k_{j} \geq \frac{\left.q m[1-(1-\beta)(T+1)]+\beta q \lambda^{P}(T+1)\right)}{r-c[q+(1-\alpha)(1-q)+(1-\beta)(T+1)(1-q) \alpha]}=: k^{(0)} .
$$

By substituting the value of the bribes $b_{j}^{N B}$ in (18) and $p_{j}^{N B}$ in (22) and by letting explicit the summations, we can rewrite the payoffs in (21) as:

$$
\underline{\Pi}=\left\{\begin{array}{l}
\Pi_{i}=(T+1)(r-c) k_{j}, \\
\Pi_{i i}=(T+1)\left\{q\left(r k_{j}-c k_{j}-m\right)+(1-q) r k_{j}-(1-q)(1-\beta)\left(c k_{j}+m\right)-\beta q \lambda^{B}\right\}, \\
\Pi_{i i i}=(T+1)\left[(r-c) k_{j}-m\right], \\
\Pi_{i v}=(T+1)\left\{q\left(r k_{j}-c k_{j}-m\right)+\right. \\
\left.+(1-q)\left[r k_{j}-(1-\alpha) c k_{j}-(1-\beta) \alpha c k_{j}\right]+(1-\beta) m q-\beta q \lambda^{P}\right\} .
\end{array}\right.
$$

A straightforward computation gives the following results. For greater clarity of the reader, we distinguish the cases of validity or not of (16). 
Proposition 3.4 Assume that (16) holds.

There exist seven capital thresholds $\xi^{(1)}, \xi^{(2)}, \xi^{(3)}, \xi^{(4)}, \xi^{(5)}, \xi^{(6)}$ such that:

(PC) If $k_{j} \in\left(\xi^{(1)}, \xi^{(2)}\right) \cup\left(\xi^{(3)}, \xi^{(4)}\right)$, then the $j$-th firm implements political corruption and the aggregate expected payoff is $\Pi_{i v}$.

(BC) If $k_{j} \in\left(\xi^{(3)}, \xi^{(5)}\right) \cup\left(\xi^{(6)},+\infty\right)$, then the $j$-th firm implements bureaucratic corruption, a bribe is agreed and the aggregate expected payoff is $\Pi_{i i}$.

(C) Otherwise, the $j$-th firm complies and the aggregate expected payoff is $\Pi_{i}$.

Proof. The game is solved using backward induction, which enables the sub-game perfect equilibria (Selten, 1975) to be obtained. The occurring cases will be distinguished.

Case I: condition (25) holds.

The cases of bureaucratic and political corruption leads to two sub-games which will be treated separately. Then, they will be opportunely gathered together at the initial stages of the decision tree.

Fix a level of time $t=0,1, \ldots, T$.

$(3 B-I) \quad$ At stage three, the $j$-th firm negotiates the bribe if and only if

$$
\mathbf{E}\left[\pi_{B}^{(F)}\right]-\pi_{2}^{(F)}>0 .
$$

Condition (27) is verified when:

$$
k_{j}>\frac{1}{c}\left(\frac{q \lambda^{B}-m(1-q)}{1-q}\right)=: k^{(4)} .
$$

$(2 B-I) \quad$ Ascending the decision-making tree, at stage two the bureaucrat decides whether to ask for a bribe or not. The bureaucrat knows that if she/he asks for a bribe, then the bribe will be negotiated when $k_{j}>k^{(4)}$, and refused otherwise.

$(2 B-I .1) \quad$ If $k_{j}>k^{(4)}$, then the bureaucrat asks for a bribe if and only if

$$
\mathbf{E}\left[\pi_{B}^{(B)}\right]-\pi_{2}^{(B)}>0
$$

which is always verified.

$(2 B-I .2) \quad$ If $k_{j} \leq k^{(4)}$, then the bureaucrat asks for a bribe if and only if

$$
\pi_{2}^{(B)}-\pi_{2}^{(B)}>0
$$

which is never verified.

$(3 P-I) \quad$ At stage three, the politician must decide whether change the regulation or not. The regulation is changed if and only if (16) holds (see Proposition 3.1).

$(2-I) \quad$ Ascending the decision tree, at stage two the $j$-th firm must decide whether to implement political corruption or bend the rule. We need to distinguish the different cases. The considered payoffs are, naturally, those at time $T$. 
(2 - I.1) If (16) is verified and $k_{j} \geq k^{(4)}$, then the $j$-th firm implements political corruption if and only if

$$
\Pi_{i v}-\Pi_{i i}>0
$$

which leads to

$$
k_{j}<k^{(1)}:=\frac{(1-\beta) m+\beta q \lambda^{B}-\beta q \lambda^{P}}{\beta(1-q)(1-\alpha) c} .
$$

$(2-I .2) \quad$ If (16) is true and $k_{j}<k^{(4)}$, then the $j$-th firm implements political corruption when

$$
\Pi_{i v}-\Pi_{i i i}>0,
$$

which leads to

$$
k_{j}>k^{(5)}:=\frac{\beta q \lambda^{P}-m(1-\beta q)}{\beta(1-q) \alpha c} .
$$

(2-I.3) If (16) does not hold and $k_{j} \geq k^{(4)}$, then the $j$-th firm complies if:

$$
\Pi_{i}-\Pi_{i i}>0
$$

which can be written as:

$$
k_{j}<k^{(3)}:=\frac{m[1-\beta(1-q)]+\beta q \lambda^{B}}{(1-q) \beta c} .
$$

(2 I.4) If (16) does not hold and $k_{j}<k^{(4)}$, then the $j$-th firm complies if:

$$
\Pi_{i}-\Pi_{i i i}>0
$$

which is trivially true.

$(1-I)$ At stage one, the $j$-th firm must decide whether to comply with regulation or not. To proceed, we need to observe the cases occurring in the previous stage.

$(1-I .1) \quad$ If (16) holds, $k_{j} \geq k^{(4)}$ and $k_{j} \leq k^{(1)}$, then the $j$-th firm complies when:

$$
\Pi_{i}-\Pi_{i v}>0,
$$

which gives

$$
k_{j}<k^{(2)}:=\frac{m q+q \lambda^{P}}{(1-q) \alpha c} .
$$


(1 - I.2) If (16) holds, $k_{j} \geq k^{(4)}$ and $k_{j}>k^{(1)}$, then the $j$-th firm complies when:

$$
\Pi_{i}-\Pi_{i i}>0
$$

which leads to

$$
k_{j}<k^{(3)} .
$$

(1 - I.3) If (16) holds, $k_{j}<k^{(4)}$ and $k_{j}>k^{(5)}$, then the $j$-th firm complies when:

$$
\Pi_{i}-\Pi_{i v}>0
$$

which is then equivalent to:

$$
k_{j}<k^{(2)} .
$$

(1 - I.4) If (16) holds, $k_{j}<k^{(4)}$ and $k_{j} \leq k^{(5)}$, the $j$-th firm complies if:

$$
\Pi_{i}-\Pi_{i i i}>0
$$

which is trivially true.

( $1-I .5)$ If (16) does not hold, $k_{j} \geq k^{(4)}$ and $k_{j}<k^{(3)}$, then the $j$-th firm complies, in that it implements political corruption and the politician does not change the rule.

( $1-I .6)$ If (16) is not true, $k_{j} \geq k^{(4)}$ and $k_{j} \geq k^{(3)}$, then the $j$-th firm complies when:

$$
\Pi_{i}-\Pi_{i i}>0
$$

which is never verified in this case.

$(1-I .7)$ If (16) does not hold and $k_{j}<k^{(4)}$, we are in the same case of $(1-I .5)$ and the firm complies.

Case II: condition (25) does not hold.

A great part of this analysis is shared with previous case. We collect here the results for the convenience of the reader.

(3-II) At stage three, the $j$-th firm negotiates the bribe if and only if $k_{j} \geq k^{(4)}$.

$(2-I I)$ Ascending the decision-making tree, at stage two the bureaucrat decides whether to ask for a bribe or not.

(2-II.1) If $k_{j} \geq k^{(4)}$, then the bureaucrat asks always for a bribe.

$(2-I I .2)$ If $k_{j}<k^{(4)}$, then the bureaucrat never asks for a bribe.

$(1-I I) \quad$ At stage one, the $j$-th firm must decide whether to comply with regulation or bend the rule. $(1-I I .1) \quad$ If $k_{j} \geq k^{(4)}$, the firm complies if and only if

$$
\Pi_{i}-\Pi_{i i}>0
$$


Condition (46) is verified when:

$$
k_{j}<k^{(3)} \text {. }
$$

$(1-I I .2) \quad$ If $k_{j}<k^{(4)}$, the firm complies when

$$
\Pi_{i}-\Pi_{i i i}>0
$$

which is always verified.

Now, it is sufficient to set the values of the thresholds to:

$$
\left\{\begin{array}{l}
\xi^{(1)}=k^{(1)}, \\
\xi^{(2)}=\max \left\{k^{(0)}, k^{(2)}, k^{(4)}\right\}, \\
\xi^{(3)}=k^{(4)}, \\
\xi^{(4)}=\max \left\{k^{(0)}, k^{(2)}, k^{(5)}\right\}, \\
\xi^{(5)}=\max \left\{k^{(0)}, k^{(3)}\right\}, \\
\xi^{(6)}=\max \left\{k^{(0)}, k^{(1)}, k^{(3)}, k^{(4)}\right\} .
\end{array}\right.
$$

If the condition (16) does not hold, we obtain the following proposition:

Proposition 3.5 Assume that (16) does not hold and consider the threshold $\xi^{(2)}$ defined in Proposition 3.4. Then:

(BC) If $k_{j} \geq \xi^{(2)}$, then the $j$-th firm implements bureaucratic corruption, a bribe is agreed and the aggregate expected payoff is $\Pi_{i i}$.

(C) Otherwise, the $j$-th firm complies and the aggregate expected payoff is $\Pi_{i}$.

The proof is similar to - and simpler than - the previous one. It is omitted.

Propositions 3.4 and 3.5 show the existence of some capital and probability thresholds beyond which the perfect Nash equilibria in the sub-games are obtained. As already illustrated above, the payoffs describe three different situations:

- $\Pi_{i}$ is the honest behaviour, in which the firm complies.

- $\Pi_{i i}$ is the payoff for bureaucratic corruption, when a bribe is agreed upon by the firm and the bureaucrat.

- $\Pi_{i v}$ is the payoff for the political corruption when the lobbying activity takes place, and the politician changes the regulation.

The results show that, in line with the theoretical and empirical literature, the size of the firm, i.e. its capital level, is a necessary condition for political corruption. But, differently from previous literature, 
TABLE 1. Values of the thresholds in different cases. The values of the parameters which are relevant in the solution of the game are expressed in bold (see Proposition 3.4 and Fig. 3)

\begin{tabular}{llcrrrrr}
\hline Label & Parameters & \multicolumn{1}{c}{$k^{(0)}$} & \multicolumn{1}{c}{$k^{(1)}$} & \multicolumn{1}{c}{$k^{(2)}$} & $k^{(3)}$ & \multicolumn{1}{c}{$k^{(4)}$} & \multicolumn{1}{c}{$k^{(5)}$} \\
\hline Par $_{1}$ & $\alpha=0.2, q=0.2, \beta=0.85$ & 0.38 & 0.27 & 2.5 & $\mathbf{0 . 7 2}$ & -0.75 & -4.85 \\
Par $_{2}$ & $\alpha=0.8, q=0.2, \beta=0.85$ & 0.36 & $\mathbf{1 . 1 0}$ & $\mathbf{0 . 6 3}$ & 0.72 & -0.75 & -1.21 \\
Par $_{3}$ & $\alpha=0.2, q=0.8, \beta=0.85$ & 1.54 & 1.10 & 40.00 & $\mathbf{8 . 8 8}$ & 3.00 & 10.59 \\
Par $_{4}$ & $\alpha=0.8, q=0.8, \beta=0.85$ & 1.52 & 4.41 & 10.00 & $\mathbf{8 . 8 8}$ & 3.00 & 2.65 \\
Par $_{5}$ & $\alpha=0.2, q=0.2, \beta=0.15$ & -0.28 & $\mathbf{8 . 8 5}$ & $\mathbf{2 . 5 0}$ & 7.58 & -0.75 & -39.17 \\
Par $_{6}$ & $\alpha=0.8, q=0.2, \beta=0.15$ & -1.97 & $\mathbf{3 5 . 4 2}$ & $\mathbf{0 . 6 3}$ & 7.58 & -0.75 & -9.79 \\
Par $_{7}$ & $\alpha=0.2, q=0.8, \beta=0.15$ & -0.91 & 35.42 & 40.00 & $\mathbf{3 6 . 3 3}$ & 3.00 & -126.67 \\
Par $_{8}$ & $\alpha=0.8, q=0.8, \beta=0.15$ & -1.10 & $\mathbf{1 4 1 . 6 7}$ & $\mathbf{1 0 . 0 0}$ & 36.33 & 3.00 & -31.67 \\
\hline
\end{tabular}

such a threshold value $\left(k^{(0)}\right)$ is only a necessary but not sufficient condition for the firm to find it worthwhile to engage in political corruption. In fact, having satisfied the necessary condition, firms find it worthwhile to move from political corruption to bureaucratic corruption as the size of the firm grows. The reason is that the payoff for bureaucratic corruption decreases less than that for political corruption when capital level increases. This happens because, in our model, the effectiveness of political corruption is more questionable than that of bureaucratic corruption, as the term $\alpha<1$ states.

\section{A numerical analysis of the thresholds}

This section contains a comparison among the thresholds $k$ 's by a numerical perspective.

The dataset used is: $r=100, c=30, m=30, \lambda^{B}=\lambda^{P}=30, T=4$. Following Escobari (2012), we fix a fine for the firm $m=30$, which implies a $100 \%$ fine over unpaid tax liabilities. For what regards the tax compliance, i .e. $c$, following Sanjit \& al-Nowaihi (2007), we set a tax rate of $30 \%(c=30)$.

We let $\alpha, \beta$ and $q$ vary: $\alpha=0.2 ; 0.8$ (high level of Government instability, high level of Government stability, respectively), $q=0.2 ; 0.8$ (low and high monitoring activity, respectively), $\beta=0.15 ; 0.85$ (asymmetric bargaining strength between bureaucrat/politician and firm, in favour of bureaucrat/politician and firm, respectively).

Table 1 contains the values of the thresholds $k$ 's as the parameters $\alpha, q$ and $\beta$ change. In order to be more precise, Table 1 shows eight different sets of parameters, where Par $_{i}$ denotes the set of parameters $i$, for $i=1, \ldots, 8$. Specifically, Par $_{1}-$ Par $_{4}$ consider the cases in which the bargaining power of the firms is high $(\beta=0.85)$, while Par $_{5}-$ Par $_{8}$ represent the cases in which the firms' bargaining strength is low ( $\beta=0.15$ ). Par $_{1}$, Par $_{3}$, Par $_{5}$ and Par $_{7}$ have the lower level of Government stability $(\alpha=0.2)$ and the remaining cases are associated to a high level of Government stability $\alpha=0.8$. Moreover, $\operatorname{Par}_{3}, \operatorname{Par}_{4}$, $\mathrm{Par}_{7}$ and $\mathrm{Par}_{8}$ are associated to low monitoring activity $(q=0.2)$ and the other Par's relies to high monitoring $(q=0.8)$.

In order to make the results clearer, let us rename the thresholds found for the capital critical level:

- $\quad k^{(0)}$. We call this threshold the Necessary Political Corruption Threshold (NPCT) because this is the necessary capital level for a firm to engage political corruption: if the firm's capital level $k_{j}$ is less than $k^{(0)}$, the $j$-th firm do not have the necessary capital to engage in political corruption; if the firm's capital level $k_{j}$ is greater than $k^{(0)}$, the $j$-th firm can engage in political corruption; 
- $\quad k^{(1)}$. We call this threshold the Political vs Bureaucratic Corruption Threshold (BPT) because if the firm's capital level $k_{j}$ is less than $k^{(1)}$, the $j$-th firm will find it worthwhile to engage in political corruption; if the firm's capital level $k_{j}$ is greater than $k^{(1)}$, the $j$-th firm will find it worthwhile to engage in bureaucratic corruption;

- $\quad k^{(2)}$. We call this threshold the Political Corruption vs Compliance Threshold (PCT) because if the firm's capital level $k_{j}$ is less than $k^{(2)}$, the $j$-th firm will find it worthwhile to comply with the rule; if the firm's capital level $k_{j}$ is greater than $k^{(2)}$, the $j$-th firm will find it worthwhile to engage in political corruption;

- $\quad k^{(3)}$. We call this threshold the Bureaucratic Corruption vs Compliance Threshold BCT because if the firm's capital level $k_{j}$ is less than $k^{(3)}$, the $j$-th firm will find it worthwhile to comply with the rule; if the firm's capital level $k_{j}$ is greater than $k^{(3)}$, the $j$-th firm will find it worthwhile to engage in bureaucratic corruption.

By looking at Table 1, $\mathrm{Par}_{1}-\mathrm{Par}_{4}$ represent cases with $\beta=0.85$, i.e. higher bargaining power of the firm versus both the bureaucrat and politician. Therefore, in such cases, ceteris paribus, the firm will have a high incentive not to comply with regulations and engage in political or bureaucratic corruption. Conversely, when $\beta=0.15$, the bargaining strength of the firm is low and therefore, the firm has a low incentive, ceteris paribus, not to comply. It is worth to observe that when the bargaining strength of the firms is low, i.e. Par $_{5}-$ Par $_{8}$, then the low-level of political bribe leads to $k^{(0)}<0$. In these cases, the entire set of firms is able to perform political corruption, since it is economically very sustainable.

As for the monitoring level $q$, a high level of control ( $q=0.8$ in our model) implies that it is less convenient for the firm, ceteris paribus, not to comply; the opposite is true for low levels of monitoring.

As already said, the parameter $\alpha$ represents the long-term effectiveness of political corruption. Hence, ceteris paribus, a high level of $\alpha$ ( $\alpha=0.8$, in our model) implies that the firm will find it worthwhile to put in place political corruption rather than bureaucratic one and viceversa, for low levels of $\alpha$.

In the cases $\mathrm{Par}_{1}, \mathrm{Par}_{3}, \mathrm{Par}_{4}$ and $\mathrm{Par}_{7}$, we have only one relevant capital level $k^{(3)}$ : if the $j$-th capital level is less than $k^{(3)}$, then the $j$-th firm will find it worthwhile to comply and viceversa if $k_{j}$ is greater than $k^{(3)}$. This happens because there is a low incentive to engage in political corruption: in fact, the threshold value $k^{(2)}$ is lower than the threshold value $k^{(1)}$. In this case the incentive of political corruption disappears since the effectiveness of political corruption is low ( $\alpha=0.2$ for $\operatorname{Par}_{1}, \mathrm{Par}_{3}$ and $\mathrm{Par}_{7}$ ) or is high but in the presence of a high control $\left(q=008\right.$ for $\left.\mathrm{Par}_{4}\right)$.

Figure 3 provides a quick look of how the game solution varies with the parametrizations. The only case of validity of Condition 16 is reported, being the other case simple.

By analysing Proposition 3.4 and comparing its results with the numerical values of Table 1 (see Fig. 3), it is evident that $k^{(1)}>k^{(2)}$ is the only condition leading to political corruption equilibrium. In this case, we obtain a compliance equilibrium for low capital level $\left(k_{j}<k^{(2)}\right)$, a political corruption equilibrium for intermediate capital level $\left(k^{(2)}<k_{j}<k^{(1)}\right)$ and a bureaucratic corruption equilibrium for high capital level $\left(k_{j}>k^{(1)}\right)$.

As for the compliant behaviour, it is worth noticing that the 'compliance capital range' is wide when the monitoring level is high: in fact, $\operatorname{Par}_{7}$ (compliance for $k_{j}<k^{(3)}=36.33$ ), Par $_{8}$ (compliance for $k_{j}<k^{(2)}=10$ ) and $\mathrm{Par}_{3}$ and $\mathrm{Par}_{4}$ (compliance for $k_{j}<k^{(3)}=8.88$ ) present the largest 'compliance capital range'. The 'compliance capital range' is lowest when the level of monitoring is low $(q=0.2)$ and the effectiveness of political corruption is high $\left(\mathrm{Par}_{2}\right.$ and $\left.\mathrm{Par}_{6}\right)$.

Bureaucratic corruption, ceteris paribus, is high when the bargaining power of the firm is high, the monitoring level is low, and political corruption is unattractive $(\alpha=0.2)$. Viceversa, political corruption, 

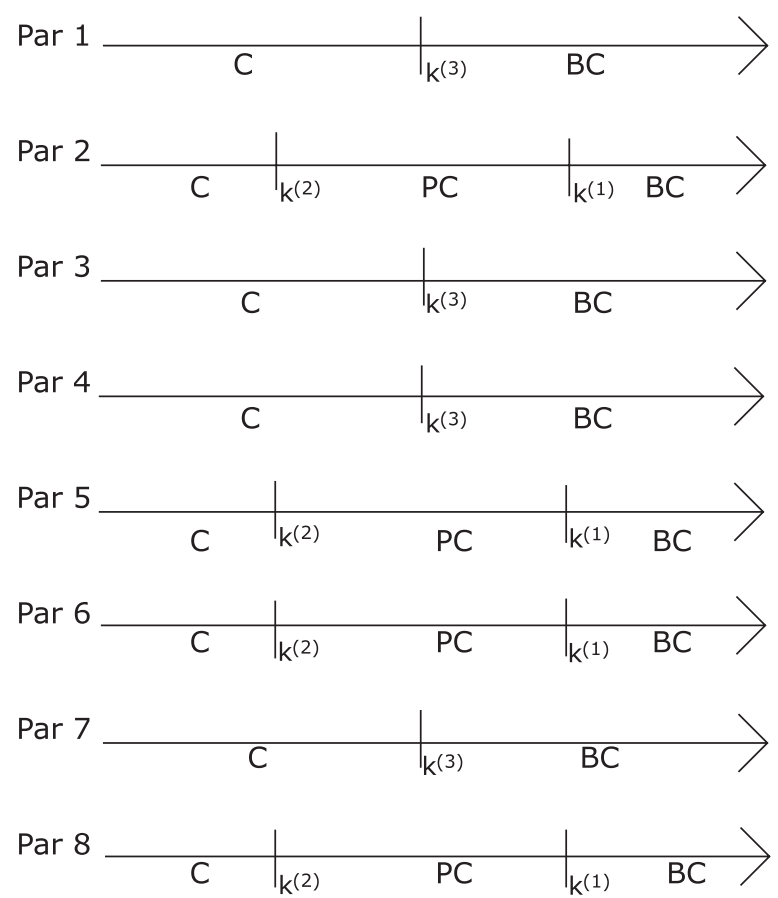

FIG. 3. Scheme of the relevant thresholds for the case of validity of Condition 16 and in the eight cases Par's. C, PC and BC stand for compliance, political corruption and bureaucratic corruption, respectively.

ceteris paribus, is more attractive with respect to bureaucratic corruption when the effectiveness of political corruption is high $(\alpha=0.8)$. In the light of the above, it is clear why the cases with greater 'political corruption capital range' are $\mathrm{Par}_{6}$ and $\mathrm{Par}_{8}$, while cases with greater 'bureaucratic corruption capital range' are $\mathrm{Par}_{1}, \mathrm{Par}_{2}, \mathrm{Par}_{5}$, and $\mathrm{Par}_{3}$ and $\mathrm{Par}_{4}$.

\section{Aggregation of capital}

This section aims at providing some insights on the relationship between political corruption, bureaucratic corruption and the industrial structure of the Country in which firms are placed.

We assume that the firms have a Gamma law distribution, based on capital levels. The decision to employ a Gamma distribution is basically driven by the capacity of this probability law to capture different situations. Indeed, Gamma has non-negative support and depends on two non-negative parameters $h$ and $\theta$, representing the shape and the scale, respectively. The variation of $h$ and $\theta$ drives the shape of the density function of a Gamma distribution, and this allows one to describe countries with high concentration of small firms, majority of large firms or mixed situations of a fair distribution among small and large firms.

It is also important to note that Gamma distribution is rather simple to treat. Hence, it is not characterized by mathematical intractability, which is the main concern when performing numerical studies. To conclude, we feel that the Gamma distribution can effectively account for the entire set of characteristics of our economic system and is also easy to treat. For this reason, it is particularly suited for carrying out intuitive numerical simulations to validate our theoretical results. 
Given $h, \theta>0$, we then denote $X \sim \Gamma(h, \theta)$, and the probability density function is

$$
f(x)=\frac{x^{h-1} \exp \{-x / \theta\}}{\Gamma(\theta, h)}, \quad x>0
$$

where $\Gamma(\theta, h)$ is a normalizing constant. We here perform some numerical experiments to assess the relevance of compliance behaviour, bureaucratic corruption and political corruption, as coming out from Proposition 3.4. To capture different cases of industrial districts, we consider four cases: $h=1, \theta=5$; $h=5, \theta=2 ; h=10, \theta=3 ; h=15, \theta=5$. The first case represents a Country with mostly small firms, while the second one, represents a country with mostly big companies. Intermediate cases are associated to a more balanced proportion between large and small firms, with more small firms in case 2 and more large ones in case 3.

We adopt the data set used in the previous Section. The truncation of the capitals, when needed in the numerical computation of the integrals (see below), is reasonably performed at $K=1000$.

Thus, the aggregation of the capital levels divides the space is three regions:

$$
P C+B C+C=1
$$

where $P C, B C, C$ stand for political corruption, bureaucratic corruption and compliance, and are associated to the equilibria $\Pi_{i v}, \Pi_{i i}$ and $\Pi_{i}$ respectively.

The terms of (51) can be explicitly written as follows:

$$
\left\{\begin{array}{l}
B C=\frac{1}{\Gamma(\theta, h)} \int_{\mathcal{I}_{B C}} x^{h-1} \exp \{-x / \theta\} d x \\
P C=\frac{1}{\Gamma(\theta, h)} \int_{\mathcal{I}_{P C}} x^{h-1} \exp \{-x / \theta\} d x \\
C=1-B C-P C
\end{array}\right.
$$

where:

- If condition (16) holds:

$$
\left\{\begin{array}{l}
\mathcal{I}_{B C}=\left(\xi^{(3)}, \xi^{(5)}\right) \cup\left(\xi^{(6)},+\infty\right) \\
\mathcal{I}_{P C}=\left(\xi^{(1)}, \xi^{(2)}\right) \cup\left(\xi^{(3)}, \xi^{(4)}\right) .
\end{array}\right.
$$

- If condition (16) does not hold:

$$
\left\{\begin{array}{l}
\mathcal{I}_{B C}=\left(\xi^{(2)},+\infty\right) \\
\mathcal{I}_{P C}=\emptyset
\end{array}\right.
$$

In order to provide a more significant analysis of the results, we employ the definition of the thresholds $\xi$ 's in (49) and report a discussion of values $k$ 's. 
TABLE 2. Values of PC, BC, C in the different cases. Condition (16) holds

\begin{tabular}{|c|c|c|c|c|c|}
\hline Label & Region & $h=1, \theta=5$ & $h=5, \theta=2$ & $h=10, \theta=3$ & $h=15, \theta=5$ \\
\hline & $\mathrm{PC}$ & 0 & 0 & 0 & 0 \\
\hline \multirow[t]{3}{*}{$\operatorname{Par}_{1}$} & $\mathrm{BC}$ & 0.8623 & 0.9999 & 1 & 1 \\
\hline & $\mathrm{C}$ & 0.1377 & 0.0001 & 0 & 0 \\
\hline & PC & 0.0805 & 0.0002 & 0 & 0 \\
\hline \multirow[t]{3}{*}{$\mathrm{Par}_{2}$} & $\mathrm{BC}$ & 0.7988 & 0.9997 & 1 & 1 \\
\hline & $\mathrm{C}$ & 0.1207 & 0.0001 & 0 & 0 \\
\hline & $\mathrm{PC}$ & 0 & 0 & 0 & 0 \\
\hline \multirow[t]{3}{*}{$\mathrm{Par}_{3}$} & BC & 0.1685 & 0.5438 & 1 & 1 \\
\hline & $\mathrm{C}$ & 0.8315 & 0.4562 & 0 & 0 \\
\hline & PC & 0 & 0 & 0 & 0 \\
\hline \multirow[t]{3}{*}{$\mathrm{Par}_{4}$} & $\mathrm{BC}$ & 0.1685 & 0.5438 & 1 & 1 \\
\hline & $\mathrm{C}$ & 0.8315 & 0.4562 & 0 & 0 \\
\hline & $\mathrm{PC}$ & 0.4348 & 0.4450 & 0.0009 & 0 \\
\hline \multirow[t]{3}{*}{ Par $_{5}$} & $\mathrm{BC}$ & 0.1695 & 0.5465 & 0.9991 & 1 \\
\hline & $\mathrm{C}$ & 0.3957 & 0.0085 & 0.031 & 0 \\
\hline & $\mathrm{PC}$ & 0.8781 & 1 & 0.7403 & 0.0070 \\
\hline \multirow[t]{3}{*}{$\mathrm{Par}_{6}$} & BC & 0.0008 & 0 & 0.2597 & 0.9930 \\
\hline & $\mathrm{C}$ & 0.1211 & 0 & 0 & 0 \\
\hline & PC & 0 & 0 & 0 & 0 \\
\hline \multirow[t]{3}{*}{$\mathrm{Par}_{7}$} & $\mathrm{BC}$ & 0.0007 & 0.0001 & 0.2329 & 0.9921 \\
\hline & $\mathrm{C}$ & 0.9993 & 0.9999 & 0.7671 & 0.0079 \\
\hline & PC & 0.1348 & 0.4409 & 0.9977 & 0.9977 \\
\hline \multirow[t]{2}{*}{ Par $_{8}$} & $\mathrm{BC}$ & 0 & 0 & 0 & 0 \\
\hline & $\mathrm{C}$ & 0.8652 & 0.5591 & 0.0023 & 0.0023 \\
\hline
\end{tabular}

Differently from Harstad \& Svensson (2011), we have taken into account differences in capital levels. This allow us to take into account different industrial structures. Specifically, the quantities in (52) are computed for the entire set of cases presented in Table 1, and for the four cases of Gamma distributions mentioned above: $h=1, \theta=5 ; h=5, \theta=2 ; h=10, \theta=3 ; h=15, \theta=5$. In Table 2, the results are presented for the case in which condition (16) is valid.

As already argued above, ceteris paribus, industrial structures with a significant number of small firms (i.e. $h=1, \theta=5$ ) show higher compliance in the case of low firm capital level. Political corruption, instead, is higher in the case of intermediate firm capital levels, while bureaucratic corruption is higher in the case of high capital levels. By reading Table 2 from left to right, i.e. from structures with many small firms to those with a high number of large firms, we observe a decrease in compliance and an increase in bureaucratic corruption, which definitively surpasses political corruption. Industrial structures with a high number of medium-sized firms (i.e. $h=5, \theta=2$ and $h=10, \theta=3$ ) show higher political corruption levels than other industrial structures. Bureaucratic corruption appears to be dominant in industrial structures with a majority of large firms (i.e. $h=15, \theta=5$ ). 
By reading Table 2 vertically we can perform a differentiated analysis with regard to industrial structure: the first column refers to an industrial structure with a prevalence of small firm, the second column considers a prevalence of medium-sized firms, while the latter column represents an industrial structure with a prevalence of large firms. We consider now the policy recommendations to ht corruption. In general, it should be noted that the two types of corruption are, at firm level, substitutes. Therefore, strategies aiming at eliminating one type of corruption might encourage the other one. For this reason, it is important to implement strategies whose target is a general increase of the level of firms' compliance. As for the industrial structure with prevalence of small firms, note that, ceteris paribus, the firms comply with regulations. From a compliance point of view, the best equilibrium is $\operatorname{Par}_{7}$ where almost all the firms comply with the rules (99.93\%). This happens because in $\operatorname{Par}_{7}$ there is a low bargaining power of the firms, a high monitoring level and a low effectiveness of lobbying. The most corrupt equilibria are $\mathrm{Par}_{2}$ and $\mathrm{Par}_{6}$ in which only the $12 \%$ of the firms comply. When the majority of firms are of medium level, the better equilibrium, i.e. greater compliance, is also in this case $\mathrm{Par}_{7}$ where the low bargaining strength of the firms, the high level of corrupt transaction monitoring combine with low effectiveness of lobbying activity, making it worthwhile to comply with the rule. Conversely, in the case of industrial structures with prevalence of large firms, it is worthwhile to engage in lobbying rather than engaging in

bureaucratic corruption or complying with regulations. In this case, it is very unlikely that firms find it worthwhile to comply with regulations and therefore it is very difficult to ht corruption.

\section{Conclusions}

This article explores the nature of political and bureaucratic corruption as alternative or coexistent choices in the same industrial environment. The probability of a punishment plays a relevant role in fighting corruption. Its value divides firms among those performing political corruption and the ones bribing bureaucrats. In addition, the results evidence the relevance of the effectiveness of political corruption. The results show that the size of the firm, i.e. its capital level, is a necessary but not sufficient condition for firms to engage in political corruption. This because, once the necessary condition is satisfied, firms find it worthwhile to move from political corruption to bureaucratic one as the size of the firm grows. This because we have considered that the results of political corruption are more uncertain than the results of bureaucratic corruption. Specifically, the corrupt politician can not grant the 'favourable' rule, due to changes in government, reinstatement of the old rules, etc. Conversely, bureaucratic corruption, since it is engage in each specific period, is less random in the results.

Because compliant behaviour is more convenient, ceteris paribus, for firms with a low capital levels, industrial structures with a significant number of small firms show a higher compliance. Industrial structures with a high number of medium-sized firms show levels of political corruption higher than other industrial structures. Bureaucratic corruption appears to be the dominant behaviour in industrial structures which a majority of large firms.

\section{REFERENCES}

Anthropelos, M., Frangos, N. E., Xanthopoulos, S. Z. \& Yannacopoulos, A. N. (2014) Contract pricing and utility sharing. IMA J. Manag. Math., 25, 329-352.

Campos, N. \& Giovannoni, F. (2007) Lobbying, corruption and political influence. Public Choice, 131, 1-21. Celentani, M. \& GanuZa, J.-J. (2002) Organized vs. competitive corruption. Ann. Oper. Res., 109, 293-315. Cerqueti, R. \& Coppier, R. (2009) Tax revenues, fiscal corruption and "shame" costs'. Econ. Model., 26, 1239-1244. CERQueti, R. \& Coppier, R. (2011) Economic growth, corruption and tax evasion. Econ. Model., 28, 489-500. CERQueti, R. \& CoppIER, R. (2013) Corruptibility and tax evasion. Eur. J. Law Econ., 39, 355-373. 
Cerqueti, R. \& Coppier, R. (2014) A game theoretical analysis of the impact of income inequality and ethnic diversity on fiscal corruption. Ann. Oper. Res., 243, 71-87.

CERqueti, R. \& CopPIER, R. (2016) Corruption, evasion and environmental policy: a game theory approach. IMA J. Manag. Math., 27, 235-253.

Cerqueti, R., Coppier, R. \& Piga, G. (2012) Corruption, growth and ethnolinguistic fractionalization: a theoretical game model. J. Econ., 106, 153-181.

Chander, P. \& Wilde, L. (1992) Corruption in tax administration. J Public Econ., 49, 333-349.

DAmANiA, R., Fredricksson P. G. \& MANI M. (2004) The persistence of corruption and regulatory compliance failures: theory and evidence. Public Choice, 121, 363-90.

Escobari, D. (2012) Imperfect detection of tax evasion in a corrupt tax administration. Public Organ. Rev., 12, 317-330.

FABRIZI, S. \& LIPPERT, S. (2012) Corruption and public display of wealth. University of Otago Economics Discussion Papers No. 1202. Available at: http://papers.ssrn.com/sol3/papers.cfm?abstract_id=2110340 (accessed 20 June 2016).

FREDRIKSSON, P. G. \& WollscheID, J. R. (2008) The political economy of investment: the case of pollution control technology. Eur. J. Polit. Econ., 24, 53-72.

GibBons, R. (1992) Game Theory for Applied Economists. Princeton, New Jersey: Princeton University Press.

Harstad, B. \& Svensson, J. (2011) Bribes, lobbying and development. Am. Polit. Sci. Rev., 105, 46-63.

Hellman, J. \& Kaufmann D. (2001) Confronting the challenge of state capture in transition economies. Finance Dev., 38, 31-35.

Hindriks, J., Keen, M. \& Muthoo, A. (1999) Corruption, extortion and evasion. J. Public Econ., 74, 394-430.

Kaufmann, D. (2009) Corruption and the global financial crisis. Brooking Institution, 27. Available at: http://www.forbes.com/2009/01/27/corruption-financial-crisis-business-corruption09_0127corruption.html (accessed 20 June 2016).

MACRAE, J. (1982) Underdevelopment and the economics of corruption: a game theory approach. World Dev., 10, 677-687.

Majumdar, M. \& Yoo, S. H. (2012) Strategic analysis of influence peddling. Int. J. Game Theory, 41, 737-762.

Mesterton-GibBons, M. (2000) An Introduction to Game-Theoretic Modelling. Rhode Island: American Mathematical Society.

Moulin, H. (1986) Game Theory for the Social Sciences, 2nd and Revised edn., New York: New York University Press.

NASH, J. F. (1950) The bargaining problem. Econometrica, 18, 155-162.

PasetTa, V. (1999) Dynamics in divide the money game with bribing. Ann. Oper. Res., 88, 361-377.

Rodrigues-Neto, J. A. (2014) On corruption, bribes and the exchange of favors. Econ. Model., 38, 152-162.

SANJIT, D. \& AL-NowaIHI, A. (2007) Why do people pay taxes? prospect theory versus expected utility theory. $J$. Econ. Behav. Organ., 64, 171-192.

Sanyal, A., Gang, I. N., \& Gosswami, O. (2000) Corruption, tax evasion and the Laffer curve. Public Choice, 105, 61-78.

SELTEN, R. (1975) Reexamination of the perfectness concept for equilibrium points in extensive games. Int. J. Game Theory, 4, 25-55. 